\title{
Leukocyte telomere length, breast cancer risk in the offspring: The relations with father's age at birth
}

\author{
Konstantin G. Arbeev ${ }^{\mathrm{a}, *}$, Steven C. Hunt ${ }^{\mathrm{b}}$, Masayuki Kimura ${ }^{\mathrm{c}}$, Abraham Aviv ${ }^{\mathrm{c}}$, Anatoliy I. Yashin $^{\mathrm{a}}$ \\ ${ }^{a}$ Center for Population Health and Aging, Duke University, Durham, NC 27708-0408, USA \\ b Cardiovascular Genetics Division, University of Utah School of Medicine, Salt Lake City, UT 84112, USA \\ ${ }^{\mathrm{c}}$ Center of Human Development and Aging, New Jersey Medical School, Newark, NJ 07103, USA
}

\section{A R T I C L E IN F O}

\section{Article history:}

Received 22 July 2010

Received in revised form 17 December 2010

Accepted 15 February 2011

Available online 25 February 2011

\section{Keywords:}

Telomeres

Breast cancer

Father's age

Offspring

Daughters

\begin{abstract}
A B S T R A C T
Recent studies have reported that leukocyte telomere length (LTL) is longer in offspring of older fathers. Longer telomeres might increase cancer risk. We examined the relation of father's age at the birth of the offspring (FAB) with LTL in the offspring in 2177 participants of the Family Heart Study and the probability of developing breast cancer in 1405 women from the Framingham Heart Study (offspring cohort). For each year of increase in FAB (adjusted for mother's age at birth), LTLs in the daughters and sons were longer by $19.4 \mathrm{bp}$ and $12.2 \mathrm{bp}$, respectively $(p<0.0001)$. Daughters of older fathers were less likely to stay free of breast cancer compared to daughters of younger fathers in empirical $(p=0.014)$ and Cox regression analyses $(p=0.0012)$ adjusted for relevant covariates. We conclude that older fathers endow their offspring with a longer LTL and their daughters with increased susceptibility to breast cancer. These independent observations cannot provide evidence for a causal relationship, mediated by telomere length, between FAB and increased breast cancer risk in daughters. However, with couples delaying having children in today's society, studies exploring the LTL association with increased breast cancer risk in daughters of older fathers might be timely and relevant.
\end{abstract}

(c) 2011 Elsevier Ireland Ltd. All rights reserved.

\section{Introduction}

Telomere length is highly variable among different species of non-human primates, but it is distinctly short in human beings in relationship to their comparatively long lifespan (Gardner et al., 2007; Kakuo et al., 1999; Steinert et al., 2002). Humans also have shorter telomeres than smaller mammals, such as rodents (Hemann and Greider, 2000), in which species with a larger body mass display somatic repression of telomerase-the reverse transcriptase that adds telomere repeats to the ends of chromosomes (Seluanov et al., 2007, 2008). Although the underlying mechanisms for these inter-species differences are not fully understood, it has been proposed that short telomeres and repression of telomerase in the soma might confer cancer resistance through replicative senescence, particularly during early life when cell replication is at its peak (Finkel et al., 2007; Stewart and Weinberg, 2006). It follows that individuals with relatively long telomeres might display increased susceptibility to cancer.

\footnotetext{
* Corresponding author at: Center for Population Health and Aging, Duke University, Trent Hall, Room 002, Box 90408, Durham, NC 27708-0408, USA. Tel.: +1 919668 2707; fax: +1 9196843861.

E-mail address: konstantin.arbeev@duke.edu (K.G. Arbeev).
}

Multiple mutations, which require manifold cell replications, are necessary for the development of cancer. But runaway cell replication entails progressive telomere shortening, which would bring about replicative senescence due to critically short telomeres. On a rare occasion, when malignant transformation does occur, it takes place only when the telomere barrier is breeched by activation of telomerase (or an alternate telomere maintenance pathway) (Finkel et al., 2007; Stewart and Weinberg, 2006). This activation does not elongate telomeres; rather it prevents further telomere shortening. Thus, most cancers display short telomeres and robust telomerase activity (Calcagnile and Gisselsson, 2007; Kim et al., 1994).

Many researchers have attached substantial weight to the short telomeres in cancerous tissues and the fact that patients with dykeratosis congenita, who display very short telomeres and 'genomic instability', are highly susceptible to cancer (Alter et al., 2009). But the genomic instability caused by exceedingly short telomeres in patients with dyskeratosis congenita hardly represents circumstances in the general population, except perhaps for telomere length in leukocytes of some of the elderly. Yet numerous investigations have been undertaken with a view that leukocyte telomere length (LTL) might be short in patients with various forms of cancer, including breast cancer (e.g., Barwell et al., 2007; De Vivo et al., 2009; Shen et al., 2007, 2009; Svenson et al., 2008). Findings of these studies have been mixed, with reports showing no 
association between LTL and breast cancer (Barwell et al., 2007; De Vivo et al., 2009; Shen et al., 2009, 2007) or longer LTL in breast cancer patients with poor outcome whose blood was collected prior to receiving chemotherapy or hormonal therapy (Svenson et al., 2008). Moreover, many of these studies were confounded by factors such as anti-cancer therapy (Schroder et al., 2001; Shen et al., 2009) and poor reproducibility of methods used to measure telomere length (Shen et al., 2007).

The present study draws on two converging lines of inquiry that link breast cancer and LTL with father's age at birth (FAB) and by implication, father age at conception. Several studies have reported that offspring of older fathers have relatively long LTL (De Meyer et al., 2007; Kimura et al., 2008; Njajou et al., 2007; Unryn et al., 2005), and the consensus is that daughters of older fathers display increased risk of developing breast cancer (Weiss-Salz et al., 2007; Xue and Michels, 2007). We hypothesize, therefore, that if LTL explains, in part, the connection between $F A B$ and breast cancer risk in the offspring, the age-dependent trajectory of this risk would be shifted towards younger age in daughters conceived by older fathers (long telomere length in individuals with older fathers may also place these individuals at higher risk of other adult cancers, e.g., hematologic malignancies, Lu et al., 2010). We proceeded in two phases to test this hypothesis. First, we examined in detail the FAB effect on the offspring's LTL in the NHLBI-Family Heart Study because this cohort has a wealth of LTL data. Second, we explored the effect of $F A B$ on the risk of breast cancer in women participating in the Offspring Study of the Framingham Heart Study ( $\mathrm{FHS}_{\text {offs }}$ ).

\section{Materials and methods}

\subsection{Cohorts}

The first phase of the study focused on the NHLBI-Family Heart Study, a multicenter investigation of the genetic and epidemiological basis of cardiovascular disease (Higgins et al., 1996). The present investigation includes only white participants with available LTL data and known parental ages, whose blood samples were collected between January 2002 and January 2004 (Table 1). We note that there were relatively few African Americans in the NHLBI-Family Heart Study with known parental age and LTL data. Moreover, the second phase of the study focused on the $\mathrm{FHS}_{\text {offs }}$ who are almost exclusively white. For this reason, our data are limited to white participants.

The Offspring Cohort of the Framingham Heart Study started in 1971 and, by 1975, a sample of 5124 offspring of participants the original Framingham cohort (and spouses of the offspring) had been enrolled in the study (2641 females, 2483 males; ages at entry: 5-70). Participants have completed examinations with intervals of four to six years and have been followed for morbidity (cardiovascular diseases and cancer) and mortality. The occurrence of diseases (including cancer) and deaths has been followed through continuous surveillance of hospital admissions, death registries, clinical exams, and other sources, so that all respective events were included in the study. Cancer sites have been coded using the International Classification of Diseases for Oncology (ICD-O-3) codes. More details on the design and selection criteria of the $\mathrm{FHS}_{\text {offs }}$ can be found elsewhere (Kannel et al., 1979).

For this study, data on six $\mathrm{FHS}_{\text {offs }}$ exams were available, with a follow-up period (since the dates of the first exam) of about 26 years. As we were interested in parental ages at birth which were available only for offspring (not their spouses), we focused only on daughters of participants of the original Framingham cohort in this study. FAB (mean 33.1 years; range 16-63 years) was computed for 1410 women as described in Section 2.4 below. Mother's age at birth (MAB) (mean 30.0 years; range 14-47 years) was computed for 1472 women. There were 1148 women with available both FAB and MAB values. Among 1410 women with available data on $\mathrm{FAB}, 52$ had data on age at diagnosis of breast cancer (the three-digit ICD-O-3 topography code: 174) during the follow-up period. We excluded data on five women with ages at onset of breast cancer younger than their ages at the first $\mathrm{FHS}_{\text {offs }}$ exam. This resulted in a sample of 1405 women with 47 breast cancer cases that was used in analyses described in Section 2.4.

\subsection{Measurement of LTL in the NHLBI-Family Heart Study}

This analysis was performed using Southern blot analysis of the terminal restriction fragment length generated by Hinf I/Rsa I restriction enzymes and the "overlay method" as recently described (Kimura et al., 2010b). Careful attention was made to randomize the samples to avoid a potential "gel effect." The coefficient of variation of this method for duplicate samples resolved on different gels on different occasions was $2.4 \%$.

\subsection{Analysis of data from the NHLBI Family Heart Study}

Regression analysis was used, adjusting for the offspring' current age at exam and testing for association of FAB and MAB with LTL. Non-independence of family members and the fact that offspring shared the same father was adjusted for by generalized estimating equations and an exchangeable correlation matrix, separately for male and female offspring, using SAS (PROC GENMOD, SAS Institute, Inc., Cary, NC).

\subsection{Analyses of data from the $F H S_{\text {offs }}$}

We performed empirical analyses of relation of $F A B$ and probability of staying free of breast cancer in daughters without adjustment for other covariates. FAB and MAB almost exclusively reflect parental ages at conception with small variations that relate to the elapsed time between conception and birth of the offspring. Parental ages at birth were evaluated using the pedigree file relating participants of $\mathrm{FHS}_{\text {offs }}$ and their parents from the original cohort of the Framingham Heart Study. As the exact dates of Exam 1 in the $\mathrm{FHS}_{\text {offs }}$ were not available for this study, the mean year of Exam 1 (1973) was used in calculations of approximate parental ages at birth.

Empirical probabilities of staying free of breast cancer (Kaplan-Meier estimates) were calculated for daughters from upper and lower halves of distribution of $F A B$ (mean FAB for the lower half of the distribution is 28.0 years and that for the upper half of the distribution is 38.2 years) in the sample and the log-rank test was performed to assess homogeneity of survival curves in the strata.

We then applied four Cox regression models to the $\mathrm{FHS}_{\text {offs }}$ data. To take into account possible effects of "social confounding" (based on evidence in the literature that people with higher socioeconomic status, e.g., better educated women, have higher risk of breast cancer), we adjusted all models for parental and daughters' education ( 1 if less than high school, 0 if high school graduate or above).

In addition, Model 1 had one covariate $F A B_{\text {dichot }}$ which equals 1 if $F A B$ is above the average age in the sample and 0 otherwise. Model 2 contained both $F B_{\text {dichot }}$

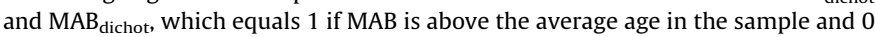
otherwise. Model 3 was used to adjust Model 2 for effects of mean BMI and smoking status ( 1 if an individual smoked cigarettes in at least one exam and 0 otherwise) of daughters. Model 4 contained one covariate $\mathrm{MAB}_{\text {dichot }}$. Note that all four models are applied to a sample of 827 offspring for whom measurements of all covariates (i.e., those included in Model 3) are available. Probabilities of staying free of breast cancer for daughters from upper and lower halves of distribution of FAB (i.e., for strata defined by $\mathrm{FAB}_{\text {dichot }}$ ) adjusted for parental and daughters' education, $\mathrm{MAB}_{\text {dichot }}$, BMI and smoking status were evaluated from the Cox regression model (Model 3). Respective survival curves were calculated at the mean values of covariates (parental and daughters' education, $\mathrm{MAB}_{\text {dichot, }} \mathrm{BMI}$, and smoking) in corresponding strata. In all models, age at the first exam was used to define left truncation (delayed entry) and individuals with ages at onset of breast cancer younger than ages at the first exam were excluded from the analyses.

Statistical analyses were performed using MATLAB (๑ MathWorks Inc.) and SAS STAT ( $\odot$ SAS Institute Inc.) software packages. $P$-values for the regression parameters in Table 3 were calculated using the Wald chi-square statistic with respect to a chi-square distribution with one degree of freedom using SAS/STAT PROC PHREG. The log-rank test $p$-value for the null hypothesis about the equality of the empirical survival curves in the strata and the estimates of the survival curves in these strata shown in Fig. 1 were calculated using SAS/STAT PROC LIFETEST.

\section{Results}

\subsection{The relation between father's age at birth and leukocyte telomere length in the offspring in the NHLBI-Family Heart Study}

Table 2 provides data about the FAB effect on LTL in adult offspring (age range in the cohort 31-86 years) based on the most recent data from our ongoing study in the NHLBI-Family Heart

Table 1

Mean \pm SD (range) of age for sons, daughters and parents in the Family Heart Study.

\begin{tabular}{|c|c|c|c|c|}
\hline Offspring & $N$ & Offspring's age & FAB & MAB \\
\hline Daughters & 1182 & $55.6 \pm 12.7(31-84)$ & $31.5 \pm 6.9(18-56)$ & $28.4 \pm 6.1(16-53)$ \\
\hline Sons & 995 & $54.7 \pm 12.9(31-86)$ & $31.4 \pm 7.3(17-69)$ & $28.2 \pm 6.2(17-46)$ \\
\hline
\end{tabular}

FAB: Father's age at the offspring's birth; MAB: Mother's age at the offspring's birth. 


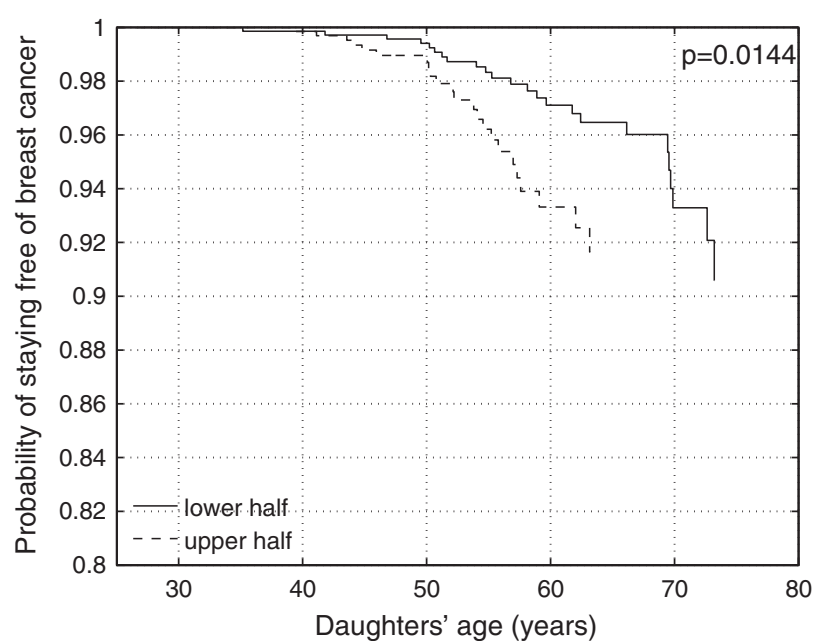

Fig. 1. Probabilities of staying free of breast cancer (Kaplan-Meier estimates) for individuals (daughters) from upper and lower halves of distribution of FAB evaluated from the empirical data (the $\mathrm{FHS}_{\text {offs }}$ sample). Numbers of individuals at risk at different ages $x$ in two strata (lower half, $N^{\text {lower }}(x)$, and upper half, $N^{\text {upper }}(x)$ ): $N^{\text {lower }}(25)=703, \quad N^{\text {upper }}(25)=702, \quad N^{\text {lower }}(50)=610, \quad N^{\text {upper }}(50)=388$, $N^{\text {lower }}(73)=62, \quad N^{\text {upper }}(63)=103$. Total numbers of cases (breast cancer incidence) in the lower and upper halves are 24 and 23, respectively. Note that the figure shows values of probability ( $y$-axis) from 0.8 to 1 (not from 0 to 1 ) to better visualize the differences between the curves.

Study. This dataset of 995 sons and 1182 daughters is considerably more extensive than that we published before on the NHLBIFamily Heart Study, which consisted of 335 sons and 492 daughters (Kimura et al., 2008).

Model A provides an account of the offspring's age on LTL. It shows that based on cross-sectional analysis, age-dependent LTL shortening was 21.5 base pairs (bp)/year for daughters and $23.1 \mathrm{bp} /$ year for sons. Model B demonstrates the profound effect of FAB on the offspring's LTL. For each year of increase in FAB, LTLs in the daughters and sons were longer by $15.5 \mathrm{bp}$ and $13.7 \mathrm{bp}$, respectively. Model $C$ shows the joint effect of $F A B$ and MAB. For each year of increase in FAB, LTLs were longer by $19.4 \mathrm{bp}$ for daughters and 12.2 bp for sons. Though when modeled independently of FAB, MAB also impacted LTL in the offspring (model D), this phenomenon was attributed to the strong correlation between $\mathrm{FAB}$ and $\mathrm{MAB}(r=0.83, p<0.0001)$. When FAB and MAB were

Table 2

Regression of the offspring's LTL on parents' ages at the offspring's birth in the Family Heart Study-995 sons and 1182 daughters.

\begin{tabular}{llrlll}
\hline & Independent & \multicolumn{1}{c}{$\beta^{\text {a }}$} & $95 \% \mathrm{Cl}(\mathrm{bp} / \mathrm{yr})$ & $p$-Value & $R^{2}$ \\
& variables & (bp/yr) & & & \\
\hline A & Daughter's age & -21.5 & -24.5 to -18.6 & $<.0001$ & 17.1 \\
B & Daughter's age & -21.9 & -24.8 to -19.0 & $<.0001$ & 19.3 \\
& FAB & 15.5 & $10.1-21.0$ & $<.0001$ & \\
C & Daughter's age & -22.1 & -25.0 to -19.2 & $<.0001$ & 19.4 \\
& FAB & 19.4 & $9.3-29.5$ & .0002 & \\
& MAB & -4.9 & -16.6 to 6.8 & 0.41 & \\
D & Daughter's age & -21.4 & -24.3 to -18.4 & $<.0001$ & 18.2 \\
& MAB & 13.4 & $7.1-19.8$ & $<.0001$ & \\
& & & & & \\
A & Son's age & -23.1 & -25.8 to -20.8 & $<.0001$ & 18.6 \\
B & Son's age & -23.0 & -25.5 to -20.5 & $<.0001$ & 21.3 \\
& FAB & 13.7 & $9.4-18.1$ & $<.0001$ & \\
C & Son's age & -22.9 & -25.4 to -20.4 & $<.0001$ & 21.3 \\
& FAB & 12.2 & $2.6-21.7$ & 0.012 & \\
& MAB & 2.0 & -9.2 to 13.2 & 0.73 & \\
D & Son's age & -22.5 & -25.1 to -20.0 & $<.0001$ & 20.8 \\
& MAB & 14.3 & $9.2-19.4$ & $<.0001$ & \\
\hline
\end{tabular}

a $\beta$ : regression coefficient.
Table 3

Estimation of Cox regression models applied to data on parents' ages at birth and incidence of breast cancer in daughters ( FHS $_{\text {offs }}$ sample).

\begin{tabular}{llll}
\hline Model & Covariate $^{\mathrm{a}}$ & Hazard ratios & $p$-Value \\
\hline Model 1 & $\mathrm{FAB}_{\text {dichot }}$ & 4.4 & 0.0015 \\
Model 2 & $\mathrm{FAB}_{\text {dichot }}$ & 5.4 & 0.0015 \\
& $\mathrm{MAB}_{\text {dichot }}$ & 0.7 & 0.43 \\
Model 3 & $\mathrm{FAB}_{\text {dichot }}$ & 5.6 & 0.0012 \\
& $\mathrm{MAB}_{\text {dichot }}$ & 0.7 & 0.41 \\
Model 4 & $\mathrm{MAB}_{\text {dichot }}$ & 1.6 & 0.27 \\
\hline
\end{tabular}

a $\mathrm{FAB}_{\text {dichot }}$ : $1(0)$ if father's age at the offspring' birth is above (below) the average age in the sample $\left(\mathrm{FHS}_{\text {offs }}\right)$; $\mathrm{MAB}_{\text {dichot }}: 1(0)$ if mother's age at the offspring's birth is above (below) the average age in the sample ( $\mathrm{FHS}_{\text {offs }}$ ). All models are adjusted for parental and daughters' education ( 1 if less than high school, 0 if high school graduate or above). In addition, Model 3 is adjusted for mean body mass index ( $\mathrm{kg} /$ $\mathrm{m}^{2}$ ) and smoking status ( 1 if smoked cigarettes in at least one exam, 0 if did not smoke cigarettes in all exams) of daughters. These covariates did not show a significant effect on the breast cancer risk in daughters in any model.

jointly considered (model C), only FAB contributed significantly to the offspring's LTL.

\subsection{The relation between father's age at conception and breast cancer} in the Offspring Study of the Framingham Heart Study

While the NHLBI-Family Study has a wealth of LTL data, we capitalized on the longitudinal nature of the $\mathrm{FHS}_{\text {offs }}$ to explore the role of $F A B$ effect on breast cancer in the daughters. In this cohort, as per the NHLBI-Family Heart Study, FAB and MAB were highly correlated $(r=0.78, p<0.0001)$.

Fig. 1 displays empirical probabilities of staying free of breast cancer for daughters from upper and lower halves of distribution of FAB evaluated from the $\mathrm{FHS}_{\text {offs }}$ sample. The log-rank test showed a significant difference between the curves $(p=0.0144)$ in that daughters of older fathers (i.e., those from the upper half of

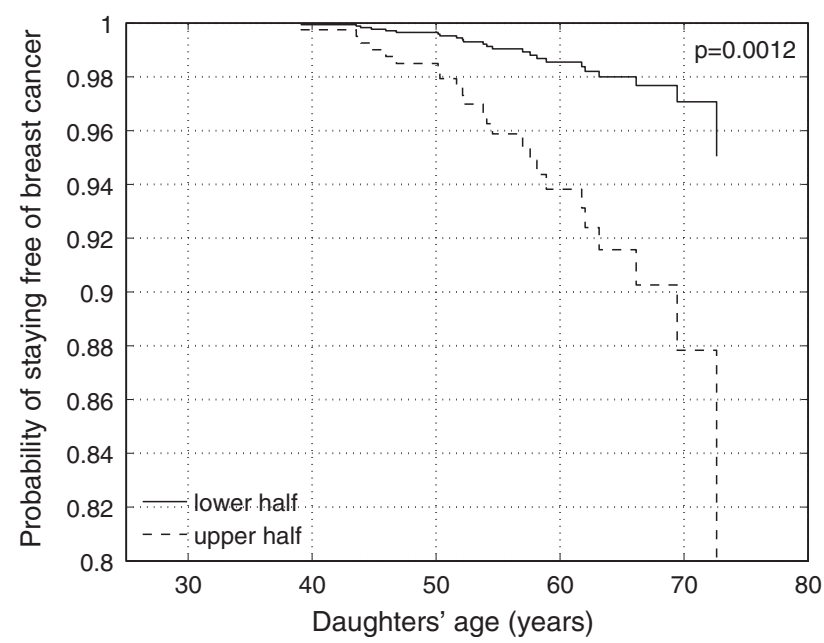

Fig. 2. Probabilities of staying free of breast cancer for individuals (daughters) from upper and lower halves of distribution of FAB adjusted for parental and daughters' education, MAB, and BMI and smoking status in daughters as evaluated from the Cox regression model (Model 3) applied to the $\mathrm{FHS}_{\text {offs }}$ sample. Respective curves are evaluated at mean values of covariates (parental and daughters' education, $\mathrm{MAB}_{\text {dichot, }} \mathrm{BMI}$, and smoking) in corresponding strata; $p$ denotes $p$-value for regression parameter $\mathrm{FAB}_{\text {dichot }}$ (see Table 3 ). Numbers of individuals at risk at different ages $x$ in two strata (lower half, $N^{\text {lower }}(x)$, and upper half, $N^{\text {upper }}(x)$ ): $N^{\text {lower }}(25)=416, \quad N^{\text {upper }}(25)=411, \quad N^{\text {lower }}(50)=377, \quad N^{\text {upper }}(50)=238$, $N^{\text {lower }}(73)=36, N^{\text {upper }}(63)=66$. Note that the numbers are different from those shown in the legend to Fig. 1 because only women with available data on FAB, MAB and all other covariates were used in Model 3. Note also that the figure shows values of probability ( $y$-axis) from 0.8 to 1 (not from 0 to 1 ) to better visualize the differences between the curves. 
distribution of $\mathrm{FAB}$ ) were less likely to stay free of breast cancer compared to daughters of younger fathers.

Results of application of Cox regression models (Models 1-4) to the $\mathrm{FHS}_{\text {offs }}$ sample are shown in Table 3. The models revealed a statistically significant effect of $\mathrm{FAB}_{\text {dichot }}$ on risks of breast cancer in daughters ( $p=0.0015$ in Models 1 and 2, $p=0.0012$ in Model 3). All other covariates in the models, including $\mathrm{MAB}_{\text {dichot }}$, did not show a significant effect on the breast cancer risk in daughters. Fig. 2 displays probabilities of staying free of breast cancer for daughters from upper and lower halves of distribution of $F A B$, adjusted for parental and daughters' education, $\mathrm{MAB}_{\mathrm{dichot}}, \mathrm{BMI}$ and smoking status as evaluated in Model 3.

\section{Discussion}

The two central findings, derived independently from the

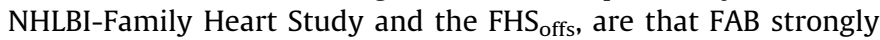
affected LTL in the offspring (both sons and daughters) and breast cancer risk in daughters. However, since these associations were observed in independent studies, there is no evidence at present that the FAB effect on daughters' susceptibility to breast cancer is mediated through telomere length.

The FAB effect on LTL in the offspring of the NHLBI-Family Heart Study not only confirmed observations by us and others (De Meyer et al., 2007; Kimura et al., 2008; Njajou et al., 2007; Unryn et al., 2005), it also underscored the considerable impact of this effect on LTL in the adult offspring, as LTL was longer by $19.4 \mathrm{bp}$ for daughters and 12.2 bp for sons per each additional year of FAB (Model C, Table 2). Though the FAB effect on the offspring's LTL is considerable, little is known about whether it is already apparent at birth or is mediated by attenuating age-dependent LTL shortening in the offspring. That said, the FAB effect must emanate from the paternal germ line. And three independent studies observed that in contrast to the progressive shortening of telomeres in replicating somatic cells, telomere length is longer in sperm of older men (Allsopp et al., 1992; Baird et al., 2006; Kimura et al., 2008). One of these studies also found evidence for the emergence of a subset of sperm with longer telomeres in older men (Kimura et al., 2008). How this feature might be translated into a longer LTL in the offspring and transmitted across generation is unknown at present.

Older FAB in the $\mathrm{FHS}_{\text {offs }}$ clearly shifted the probability of breast cancer in the daughters towards a younger age (Figs. 1 and 2). For instance, as estimated from the Cox regression model after adjustment for parental and daughters' education, MAB, smoking and BMI (Model 3, Table 3 ), by the age of 50 years $1.8 \%$ of daughters of older fathers had breast cancer. The age of daughters of younger fathers with the same proportion of breast cancer cases was 62 years. By age 55 years, $4.1 \%$ of daughters of older fathers suffered from breast cancer. The age of daughters of younger fathers with the same proportion of breast cancer cases was about 70 years.

The shift in the probability of breast cancer towards a younger age in daughters of older fathers is particularly relevant in light of the effect of FAB on LTL and given that this effect was more pronounced in daughters than in sons. In the NHLBI-Family Heart Study, when dichotomized at the mean FAB (31.4 years), LTL of daughters of older fathers was longer by $162 \mathrm{bps}$ than LTL of daughters of younger fathers $(6.988 \mathrm{~kb}$ vs. $6.826 \mathrm{~kb}$, respectively, $p=0.0002$ ). This FAB effect amounts to daughters of older fathers being younger by 7.3 years in telomeric year equivalence, based on the average rate of age-dependent LTL shortening of $22.1 \mathrm{bp} /$ year (Table 2, Model C). A similar shift in years towards younger age in the probability of having breast cancer is observed in daughters of older fathers in the $\mathrm{FHS}_{\text {offs }}$ (Fig. 2).

We were able to detect the shift towards a younger age in the probability of having breast cancer in the relatively small sample, perhaps due to the longitudinal nature of the Framingham Heart Study, which in the case of the $\mathrm{FHS}_{\text {offs }}$ sample used in this study has been going on for about 26 years. However, in light of the small number of breast cancer cases, we cannot exclude the possibility of a false positive finding. That being said and given that epidemiological data cannot infer causality from association, if the increased predilection of daughters of older fathers to breast cancer is linked to telomere biology, our findings are consistent with the concept that a longer LTL, which in large measure reflects telomere length in other cells (Gardner et al., 2007; Kimura et al., 2010a; Okuda et al., 2002), might increase the breast cancer risk.

A long LTL entails diminished susceptibility to atherosclerosis (Benetos et al., 2004; Brouilette et al., 2003, 2007; O'Donnell et al., 2008), the relationships of LTL with atherosclerosis on the one hand and breast cancer on the other hand suggest an "evolutionary" trade off, namely, more susceptibility to some forms of cancer for less susceptibility to atherosclerosis and other cardiovascular diseases (Yashin et al., 2009). It is therefore of considerable import that well-designed, adequately powered studies employing reliable methods of LTL measurements should be undertaken in cohorts with $\mathrm{FAB}, \mathrm{MAB}$ and breast cancer data with a view to resolve the controversy whether a longer LTL increases the susceptibility to breast cancer in humans.

Finally, growing numbers of not only women but also men choose to postpone parenthood, causing a demographic shift in modern societies in which, on average, both parents conceive their first child at an older age (Hamilton et al., 2005; Office of National Statistics, 2002). Therefore, the FAB effect on the offspring's LTL and health status is more than just a scientific curiosity but a phenomenon with considerable ramifications.

\section{Disclosure statement}

The authors declare no actual or potential conflicts of interest related to this paper.

\section{Acknowledgements}

The research reported in this article was supported by $\mathrm{NIH}$ Grants R01AG021593, R01AG020132, R01AG030612, R01AG027019, U01 HL67893, U01 HL67894, U01 HL67895, U01 HL67896, U01 HL67897, U01 HL67898, U01 HL67899, U01 HL67900, U01 HL67901, U01 HL67902, U01 HL56563, U01 HL56564, U01 HL56565, U01 HL56566, U01 HL56567, U01 HL56568, and U01 HL56569. The content is solely the responsibility of the authors and does not necessarily represent the official views of the NIA or the NIH. This manuscript was not prepared in collaboration with investigators of the Framingham Heart Study and does not necessarily reflect the opinions or views of the Framingham Heart Study.

\section{References}

Allsopp, R.C., Vaziri, H., Patterson, C., Goldstein, S., Younglai, E.V., Futcher, A.B., Greider, C.W., Harley, C.B., 1992. Telomere length predicts replicative capacity of human fibroblasts. Proc. Natl. Acad. Sci. U.S.A. 89 (21), 10114-10118.

Alter, B.P., Giri, N., Savage, S.A., Rosenberg, P.S., 2009. Cancer in dyskeratosis congenita. Blood 113 (26), 6549-6557.

Baird, D.M., Britt-Compton, B., Rowson, J., Amso, N.N., Gregory, L., Kipling, D., 2006 Telomere instability in the male germline. Hum. Mol. Genet. 15 (1), 45-51.

Barwell, J., Pangon, L., Georgiou, A., Docherty, Z., Kesterton, I., Ball, J., Camplejohn, R., Berg, J., Aviv, A., Gardner, J., Kato, B.S., Carter, N., Paximadas, D., Spector, T.D. Hodgson, S., 2007. Is telomere length in peripheral blood lymphocytes correlated with cancer susceptibility or radiosensitivity? Br. J. Cancer 97 (12), 16961700.

Benetos, A., Gardner, J.P., Zureik, M., Labat, C., Lu, X.B., Adamopoulos, C., Temmar, M. Bean, K.E., Thomas, F., Aviv, A., 2004. Short telomeres are associated with increased carotid atherosclerosis in hypertensive subjects. Hypertension 43 (2), $182-185$ 
Brouilette, S., Singh, R.K., Thompson, J.R., Goodall, A.H., Samani, N.J., 2003. White cell telomere length and risk of premature myocardial infarction. Arterioscler. Thromb. Vasc. Biol. 23 (5), 842-846.

Brouilette, S.W., Moore, J.S., D.McMahon, A., Thompson, J.R., Ford, I., Shepherd, J., Packard, C.J., Samani, N.J., Stu, W.S.C.P., 2007. Telomere length, risk of coronary heart disease, and statin treatment in the West of Scotland Primary Prevention Study: a nested case-control study. Lancet 369 (9556), 107-114.

Calcagnile, O., Gisselsson, D., 2007. Telomere dysfunction and telomerase activation in cancer-a pathological paradox? Cytogenet. Genome Res. 118 (2-4), 270-276.

De Meyer, T., Rietzschel, E.R., De Buyzere, M.L., De Bacquer, D., Van Criekinge, W., De Backer, G.G., Gillebert, T.C., Van Oostveldt, P., Bekaert, S., Asklepios, I., 2007. Paternal age at birth is an important determinant of offspring telomere length. Hum. Mol. Genet. 16, 3097-3102.

De Vivo, I., Prescott, J., Wong, J.Y.Y., Kraft, P., Hankinson, S.E., Hunter, D.J., 2009. A prospective study of relative telomere length and postmenopausal breast cancer risk. Cancer Epidemiol. Biomark. Prevent. 18 (4), 1152-1156.

Finkel, T., Serrano, M., Blasco, M.A., 2007. The common biology of cancer and ageing. Nature 448 (7155), 767-774.

Gardner, J.P., Kimura, M., Chai, W., Durrani, J.F., Tchakmakjian, L., Cao, X., Lu, X., Li, G., Peppas, A.P., Skurnick, J., Wright, W.E., Shay, J.W., Aviv, A., 2007. Telomere dynamics in Macaques and humans. J. Gerontol. A Biol. Sci. Med. Sci. 62, 367-374.

Hamilton, B.E., Martin, J.A., Ventura, S.J., Sutton, P.D., Menacker, F., 2005. Births: preliminary data for 2004. Natl. Vital Stat. Rep. 54 (8), 1-17.

Hemann, M.T., Greider, C.W., 2000. Wild-derived inbred mouse strains have short telomeres. Nucleic Acids Res. 28 (22), 4474-4478.

Higgins, M., Province, M., Heiss, G., Eckfeldt, J., Ellison, R.C., Folsom, A.R., Rao, D.C. Sprafka, J.M., Williams, R., 1996. NHLBI Family Heart Study: objectives and design. Am. J. Epidemiol. 143 (12), 1219-1228.

Kakuo, S., Asaoka, K., Ide, T., 1999. Human is a unique species among primates in terms of telomere length. BBRC 263 (2), 308-314.

Kannel, W.B., Feinleib, M., McNamara, P.M., Garrison, R.J., Castelli, W.P., 1979. An investigation of coronary heart disease in families: the Framingham offspring study. Am. J. Epidemiol. 110 (3), 281-290.

Kim, N.W., Piatyszek, M.A., Prowse, K.R., Harley, C.B., West, M.D., Ho, P.L.C., Coviello, G.M., Wright, W.E., Weinrich, S.L., Shay, J.W., 1994. Specific association of human telomerase activity with immortal cells and cancer. Science 266 (5193), 2011-2015.

Kimura, M., Cherkas, L.F., Kato, B.S., Demissie, S., Hjelmborg, J.B., Brimacombe, M., Cupples, A., Hunkin, J.L., Gardner, J.P., Lu, X.B., Cao, X.J., Sastrasinh, M., Province, M.A., Hunt, S.C., Christensen, K., Levy, D., Spector, T.D., Aviv, A., 2008. Offspring's leukocyte telomere length, paternal age, and telomere elongation in sperm. PLoS Genet. 4 (2), e37.

Kimura, M., Gazitt, Y., Cao, X.J., Zhao, X.Y., Lansdorp, P.M., Aviv, A., 2010a. Synchrony of telomere length among hematopoietic cells. Exp. Hematol. 38 (10), 854-859.

Kimura, M., Stone, R.C., Hunt, S.C., Skurnick, J., Lu, X.B., Cao, X.J., Harley, C.B., Aviv, A., 2010 b. Measurement of telomere length by the Southern blot analysis of terminal restriction fragment lengths. Nat. Protoc. 5 (9), 1596-1607.

Lu, Y.N., Ma, H.Y., Sullivan-Halley, J., Henderson, K.D., Chang, E.T., Clarke, C.A. Neuhausen, S.L., West, D.W., Bernstein, L., Wang, S.S., 2010. Parents' ages at birth and risk of adult-onset hematologic malignancies among female teachers in California. Am. J. Epidemiol. 171 (12), 1262-1269.
Njajou, O.T., Cawthon, R.M., Damcott, C.M., Wu, S.H., Ott, S., Garant, M.J., Blackburn, E.H., Mitchell, B.D., Shuldiner, A.R., Hsueh, W.C., 2007. Telornere length is paternally inherited and is associated with parental lifespan. Proc. Natl. Acad. Sci. U.S.A. 104, 12135-12139.

O’Donnell, C.J., Demissie, S., Kimura, M., Levy, D., Gardner, J.P., White, C., D’Agostino, R.B., Wolf, P.A., Polak, J., Cupples, L.A., Aviv, A., 2008. Leukocyte telomere length and carotid artery intimal medial thickness: the Framingham Heart Study. Arterioscler. Thromb. Vasc. Biol. 28 (6), 1165-1171.

Office of National Statistics, 2002. Birth Statistics: Review of the Registrar General on Births and Family Building Patterns in England and Wales-FM1. Stationery Office, London.

Okuda, K., Bardeguez, A., Gardner, J.P., Rodriguez, P., Ganesh, V., Kimura, M., Skurnick, J., Awad, G., Aviv, A., 2002. Telomere length in the newborn. Pediatr. Res. 52 (3), 377-381.

Schroder, C.P., Wisman, G.B.A., de Jong, S., van der Graaf, W.T.A., Ruiters, M.H.J., Mulder, N.H., de Leij, L., van der Zee, A.G.J., de Vries, E.G.E., 2001. Telomere length in breast cancer patients before and after chemotherapy with or without stem cell transplantation. Br. J. Cancer 84 (10), 1348-1353.

Seluanov, A., Chen, Z.X., Hine, C., Sasahara, T.H.C., Ribeiro, A., Catania, K.C., Presgraves, D.C., Gorbunova, V., 2007. Telomerase activity coevolves with body mass not lifespan. Aging Cell 6 (1), 45-52.

Seluanov, A., Hine, C., Bozzella, M., Hall, A., Sasahara, T.H.C., Ribeiro, A., Catania, K.C., Presgraves, D.C., Gorbunova, V., 2008. Distinct tumor suppressor mechanisms evolve in rodent species that differ in size and lifespan. Aging Cell 7 (6), 813823.

Shen, J., Terry, M.B., Gurvich, I., Liao, Y.Y., Senie, R.T., Santella, R.M., 2007. Short telomere length and breast cancer risk: a study in sister sets. Cancer Res. 67 (11), 5538-5544.

Shen, J., Gammon, M.D., Terry, M.B., Wang, Q., Bradshaw, P., Teitelbaum, S.L., Neugut, A.I., Santella, R.M., 2009. Telomere length, oxidative damage, antioxidants and breast cancer risk. Int. J. Cancer 124 (7), 1637-1643.

Steinert, S., White, D.M., Zou, Y., Shay, J.W., Wright, W.E., 2002. Telomere biology and cellular aging in nonhuman primate cells. Exp. Cell Res. 272 (2), 146-152.

Stewart, S.A., Weinberg, R.A., 2006. Telomeres: cancer to human aging. Annu. Rev. Cell. Dev. Biol. 22, 531-557.

Svenson, U., Nordfjall, K., Stegmayr, B., Manjer, J., Nilsson, P., Tavelin, B., Henriksson, R., Lenner, P., Roos, G., 2008. Breast cancer survival is associated with telomere length in peripheral blood cells. Cancer Res. 68 (10), 3618-3623.

Unryn, B.M., Cook, L.S., Riabowol, K.T., 2005. Paternal age is positively linked to telomere length of children. Aging Cell 4 (2), 97-101.

Weiss-Salz, I., Harlap, S., Friedlander, Y., Kaduri, L., Levy-Lahad, E., Yanetz, R., Deutsch, L., Hochner, H., Paltiel, O., 2007. Ethnic ancestry and increased paternal age are risk factors for breast cancer before the age of 40 years. Eur. J. Cancer Prev. 16, 549-554.

Xue, F., Michels, K.B., 2007. Intrauterine factors and risk of breast cancer: a systematic review and meta-analysis of current evidence. Lancet Oncol. 8 (12), 1088-1100.

Yashin, A.I., Ukraintseva, S.V., Akushevich, I.V., Arbeev, K.G., Kulminski, A., Akushevich, L., 2009. Trade-off between cancer and aging: what role do other diseases play? Evidence from experimental and human population studies. Mech. Ageing Dev. 130 (1-2), 98-104. 